\title{
Operation and electro(chemical) characterization of a microbial fuel cell stack fed with fermentable household waste extract
}

\author{
Tremouli A. ${ }^{1,{ }^{*}}$, Pandis P.K. ${ }^{1,2}$, Karydogiannis I. ${ }^{1}$, Stathopoulos V.N. ${ }^{2}$, Argirusis C. ${ }^{1}$ and Lyberatos G. ${ }^{1,3}$ \\ ${ }^{1}$ School of Chemical Engineering, National Technical University of Athens, Heroon Polytechniou 9, 15780, Zografou Athens, Greece \\ ${ }^{2}$ General Department, School of Sciences, National and Kapodistrian University of Athens, 34400 Psachna campus, Evia, Greece \\ ${ }^{3}$ Institute of Chemical Engineering Sciences (ICE-HT), Stadiou Str., Platani, 26504, Patras, Greece \\ Received: 19/12/2018, Accepted: 07/03/2019, Available online: 13/03/2019 \\ *to whom all correspondence should be addressed: e-mail: atremouli@chemeng.ntua.gr \\ https://doi.org/10.30955/gnj.002996
}

\section{Abstract}

Electrochemical characterization of a stack consisting of two identical membrane-less microbial fuel cells units, was investigated when operated in series and in parallel electrical configurations. Food Residue Biomass (FORBI) (FORBI; $0.8 \mathrm{~g} \mathrm{COD/L)} \mathrm{was} \mathrm{used} \mathrm{as} \mathrm{the} \mathrm{electrode} \mathrm{donor} \mathrm{in}$ the anode chamber. Linear Sweep Voltammetry (LSV) was carried out for the construction of polarization curves which revealed that the highest power output $(3.88 \mathrm{~mW})$ was obtained under parallel connection as in series connection was found lower due to voltage drop phenomena. Electrochemical Impedance Spectroscopy measurements (EIS) gave an insight in the electrochemical processes occurring within the stack under both electrical connections. The contribution of the individual resistances to the overall internal resistance was defined, designating the significant role of the solution resistance $\left(R_{s}\right)$ and the charge transfer resistance (RcT) under closed circuit conditions.

Keywords: Microbial fuel cell; stack; bioelectricity; fermentable household waste; food residue biomass product; electrochemical impedance spectroscopy (EIS).

\section{Introduction}

Microbial fuel cells (MFCs) are systems that convert biomass directly into electricity through the metabolic activity of microorganisms (Bennetto, 1990). MFCs are considered to be a promising sustainable technology since they have the advantage of generating electricity while treating wastewater (Lu et al., 2009). Although the power produced from a single MFC unit can be enhanced by the systems' architecture and the wastewater characteristics (organic matter, conductivity, $\mathrm{pH}$ etc.), it is still thermodynamically limited (Oh and Logan, 2007). Specifically, the voltage will never exceed a theoretical open circuit voltage (OCV) of $1.14 \mathrm{~V}$ as determined by the NADH $(-0.32 \mathrm{~V})$ and pure oxygen $(+0.82 \mathrm{~V})$ redox potentials (Aelterman et al., 2006).
In order to overcome the thermodynamic barrier and maximize the power generated from MFC systems, several MFC units can be connected in series or/and in parallel so to increase the voltage or/and the current, respectively (Papaharalabos et al., 2014; Tremouli et al., 2018). However, stacking MFC units carries its own challenges such as cell voltage reversal. Voltage reversal occurs when one of the cells exhibits a much larger resistance than other cells in the stack (Oh and Logan, 2007). It therefore becomes vital to understand the phenomena occurring in such stacks in order to avoid this phenomenon (Greenman et al., 2011). Electrochemical Impedance Spectroscopy (EIS) has proved to be a powerful technique which can give an insight to the electrochemical phenomena in fuel cells (Gasparyan et al., 2009; Gasparyan et al., 2011; Pandis et al., 2016a; Pandis et al., 2016b). Its use has become a valuable and in depth understanding tool for phenomena occurring in individual MFC units so as in MFC stacks (Zhao et al., 2009; Hidalgo et al., 2015; Santoro et al., 2017).

In this research a stacked MFC; consisting of two identical (four air-cathode single chamber membrane-less MFCs), was studied. The stack consists of two MFC units connected together, based on the design of the four-air cathode MFC configuration (4ACMFC) (Tremouli et al., 2015; Tremouli et al., 2016).

EIS experiments were performed in order to investigate the phenomena occurring within the stack under two different electrical configurations (in series and in parallel) and their influence on the power output of the stack. The stack was fed with a water extract from fermentable household food waste (FORBI) $\left(0.8 \mathrm{~g} \mathrm{COD} \mathrm{L}^{-1}\right)$ as substrate. FORBI was produced by household food waste collected from the Municipality of Halandri, Athens, Greece (Chatzikonstantinou et al., 2018; Ntaikou et al., 2018). Measurements included Open Current Voltage (OCV) data recording, Linear Sweep Voltammetry (LSV) curves and Electrochemical Impedance Spectroscopy (EIS) characterization under parallel and series electrical connection of the stack. 


\section{Materials and methods}

\subsection{MFC set-up}

Figure 1 shows the two identical single chamber MFC units. Each unit has a working volume of $120 \mathrm{ml}$ each and was fabricated using multiple cathode electrodes as previously described (Tremouli et al., 2019). Each MFC unit was composed of a single cubical chamber and four plexiglas tubes run through the chamber, providing a structural support to the separator. Additional construction details can be found elsewhere (Tremouli et al., 2019). Each cell was filled with graphite granules ( $\varnothing 1.5-5 \mathrm{~mm}$, type 00514, Le Carbone, Belgium), serving as the anodic biofilm support and conducting material (conveying electrons to the graphite rod placed through the packed bed of granules). Prior to use, the granules were washed for $24 \mathrm{~h}$ in $32 \% \mathrm{HCl}$ and the process was repeated four times (Freguia et al., 2007). GORE-TEX cloth was used as separator and as support of the cathode electrocatalyst. The cloth was made electrically conductive and catalytically active using the method described by Zhuang et al. (Zhuang et al., 2009) with $\mathrm{MnO}_{2}$ deposition as the catalyst at a loading of $89 \mathrm{mg}$ $\mathrm{cm}^{-2}$. The stack was finalized by wiring in parallel and/or in series connection the two identical MFC units.

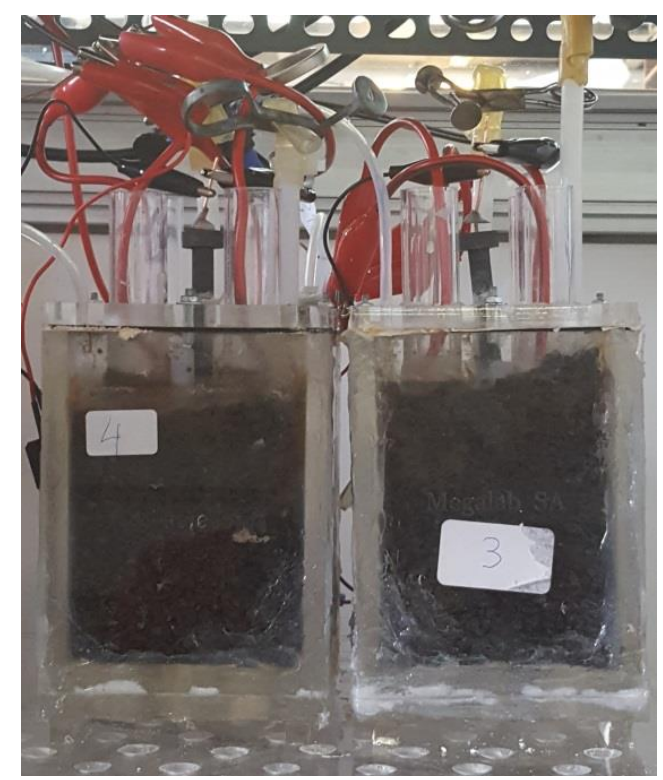

Figure 1. Photo of the two identical MFC units

\subsection{MFC start-up and stack operation}

The two MFC units were initially enriched and operated under the same conditions. In particular, the enrichment and adaptation of the electrochemically active bacteria in the MFCs were performed in batch mode, under a fixed external load of $0.1 \mathrm{k} \Omega$ for each cell. During inoculation, $10 \%(\mathrm{v} / \mathrm{v})$ of anaerobic sludge obtained from the Athens (Greece) Wastewater Treatment Plant and glucose (1.6 $\mathrm{g} \mathrm{COD} \mathrm{L}^{-1}$ ) was used as the feedstock. Following the inoculation period glucose (three batch cycles) was replaced by FORBI extract $\left(0.8 \mathrm{~g} \mathrm{COD} \mathrm{L}^{-1}\right)$, without further addition of sludge. FORBI was produced by drying and shredding the pre-sorted fermentable fraction of household food waste collected door-to-door in the Municipality of Halandri, Athens, Greece (Chatzikonstantinou et al., 2018; Ntaikou et al., 2018; Tremouli et al., 2019).

After establishing stable operation of each MFC unit, the $0.1 \mathrm{k} \Omega$ external resistive load was removed and a $0.05 \mathrm{k} \Omega$ load and $0.2 \mathrm{k} \Omega$ were connected to the stack, for the parallel and the series connection, respectively. The stack was operated in batch mode. Electrode output for each MFC was individually recorded, in 1 min intervals, in volts (V) versus time using a data acquisition system (Advantech ADAM- 4019+).

\subsection{Electrical/electrochemical characterization}

Electrochemical Impedance Spectroscopy (EIS) measurements were conducted using a potentionstat galvanostat (BIOLOGIC SP-150) equipped with a frequency response analyzer (FRA). The measurements concerned the entire stack and a two-electrode set-up was used using the anode as the working electrode and the cathode as the reference and counter electrode (Figure 2). EIS data were collected over the frequency range of $100 \mathrm{kHz}-1 \mathrm{mHz}$, using a stimulus of $10 \mathrm{mV}$ amplitude. The above experiments were performed at OCV and when the cell voltage reached its steady-state value following the addition of FORBI $(0.38 \mathrm{~V}$ - series connection, $0.25 \mathrm{~V}$ parallel connection), and when the stack voltage reached approximately the value of $0.15 \mathrm{~V}$ for both connections. The equivalent electrical circuit applied for the calculation of internal resistances is depicted in Figure 3. A two - time constant model equivalent circuit was determined, considering the overall solution resistance of the cell (Rs) in series with two parallel RC components followed by a Warburg element (W). Linear Sweep Voltammetry (LSV) from open current voltage (OCV) to short-circuit of the cell was carried out for the construction of polarization curves in order to assess the stack performance.
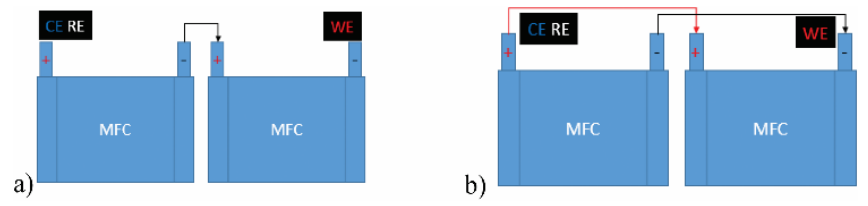

Figure 2. a) Series and b) parallel connections of MFCs (WE=working electrode, $\mathrm{CE}=$ counter electrode, $\mathrm{RE}=$ Reference electrode)

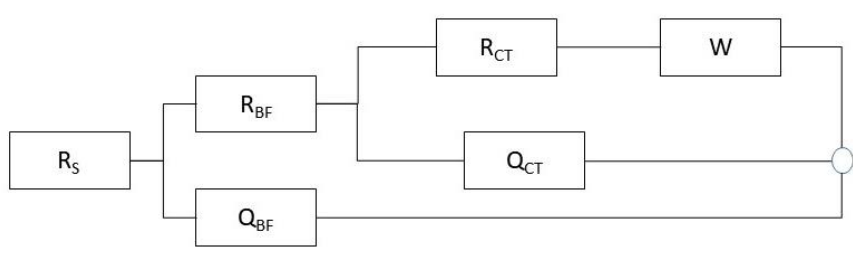

Figure 3. Equivalent circuit for interpolation of EIS experiments in MFC stacks ( $R_{S}$ : solution resistance of the cell, $R_{C T}$ : charge transfer resistance, $\mathrm{R}_{\mathrm{BF}}$ : biofilm resistance, $\mathrm{R}_{\mathrm{INT}}$ : calculated internal resistance of cell, $\mathrm{Q}_{\mathrm{CT}}$ : charge transfer capacitance, $\mathrm{Q}_{\mathrm{BF}}$ : biofilm capacitance, W:diffusion resistance (Warburg element)) 


\section{Results and discussion}

3.1. Effect of electrical connection on the polarization performance of the stack

Table 1 shows the open circuit voltage (OCV) and the maximum power $\left(P_{\max }\right)$ which were achieved from the single MFC unit, as previously studied, and the stack, under series and parallel electrical connections. The data were obtained after the voltage had leveled off to a practically constant value, following the addition of the FORBI waste in the anolyte.

Table 1. Open circuit voltage and maximum power produced from a single MFC unit and the stack under two different electrical connections (series and parallel)

\begin{tabular}{cccc}
\hline & $\begin{array}{c}\text { MFC unit } \\
\text { (Tremouli } \text { et } \\
\text { al., 2019) }\end{array}$ & $\begin{array}{c}\text { stack/series } \\
\text { electrical } \\
\text { connection }\end{array}$ & $\begin{array}{c}\text { stack/parallel } \\
\text { electrical } \\
\text { connection }\end{array}$ \\
\hline OCV (V) & 0.50 & 0.77 & 0.49 \\
\hline $\begin{array}{c}\text { Pmax } \\
(\mathrm{mW})\end{array}$ & 2.54 & 2.56 & 3.88 \\
\hline
\end{tabular}

From Table 1 it can be clearly observed that the OCV value $(0.77 \mathrm{~V})$ for the stack operation under series connection, is lower than the OCV value which results from using Ohm's law $(\sim 1.0 \mathrm{~V})$. That is, the overall voltage of two components in series equals the sum of voltages of each component (Ramasamy and Sekar, 2013). The limited performance under series connection is also observed on the polarization curve in Figure 4a. In particular, the polarization curve under series connection lacks the linearity in comparison with the parallel connection of the MFC units (Figure 4b). This is probably due to the activation losses which occur during the early stages of the stack operation under series connection, which results in a decrease of the overall system performance. Thus the overall maximum power output of the stack is $2.56 \mathrm{~mW}$ which equals the maximum power output of the single MFC cell ( $2.54 \mathrm{~mW})$.

On the other hand, in parallel connection, the OCV value of the stack equals the OCV of the single unit, a result which is in agreement with Ohm's law. The linearity of the polarization curve in the parallel connection case (Figure 4b) indicates that no activation losses were present in the cell stack and the total power output reached the value of $3.88 \mathrm{~mW}$. The different values of power output for both series and parallel connection needs to be further analyzed while such phenomenon has occurred in stack connections (Oh and Logan, 2007). As power output should be equal for both connections, it is assumed that a voltage reversal in series connections Table 2. Fitted parameters from EIS curves

\begin{tabular}{cccccccc}
\hline \multirow{2}{*}{ Fitted Parameters } & \multicolumn{3}{c}{ Series Connection } & \multicolumn{3}{c}{ Parallel Connection } \\
\cline { 2 - 8 } & @ 0.76 V (OCV) & $@ \mathbf{0 . 3 8 ~ V}$ & @ 0.15 V & @ 0.45 V (OCP) & @ 0.25 V & @ 0.12 V \\
\hline $\mathrm{R}_{\mathrm{S}}(\Omega)$ & 21.45 & 18.80 & 19.06 & 4.96 & 4.83 & 4.86 \\
\hline $\mathrm{R}_{\mathrm{BF}}(\Omega)$ & 4.19 & 3.74 & 3.69 & 1.7 & 0.75 & 0.86 \\
\hline $\mathrm{C}_{\mathrm{BF}}(\mathrm{F})$ & $36 \cdot 10^{-6}$ & $0.7 \cdot 10^{-6}$ & $0.8 \cdot 10^{-6}$ & $0.7 \cdot 10^{-3}$ & $3 \cdot 10^{-6}$ & $9 \cdot 10^{-6}$ \\
\hline $\mathrm{C}_{\mathrm{CT}}(\mathrm{F})$ & $10 \cdot 10^{-3}$ & $65.5 \cdot 10^{-6}$ & $0.1 \cdot 10^{-3}$ & $4 \cdot 10^{-3}$ & $0.9 \cdot 10^{-3}$ & $2.2 \cdot 10^{-3}$ \\
\hline $\mathrm{R}_{\mathrm{CT}}(\Omega)$ & 4.65 & 4.03 & 4.58 & 2.53 & 1 & 1 \\
\hline $\mathrm{R}_{\mathrm{INT}}(\Omega)(\mathrm{calc})$ & 30.29 & 26.58 & 27.26 & 9.18 & 6.59 & 6.74 \\
\hline
\end{tabular}

adversely affected bacteria on the anode of one of the cells leading to batch cycle starvation.

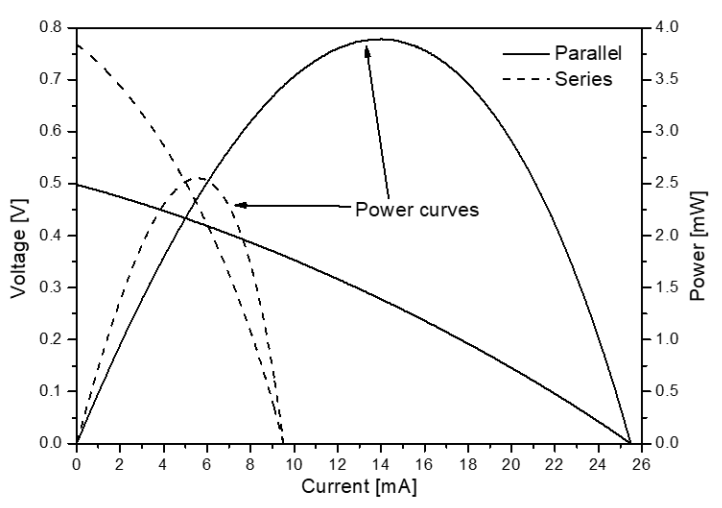

Figure 4. Power and polarization curves for the stack under series connection and parallel connection

\subsection{Electrochemical impedance spectroscopy characterization}

The EIS experiments were carried out at OCV when the stack voltage had reached its maximum value and when the stack voltage reached approximately the value of $0.15 \mathrm{~V}$. The stack under both electrical configurations was considered as a unified cell using the same two - time constant model equivalent circuit (Figure 3) as for the individual MFC unit (Tremouli et al., 2019). Fitting of the curves yielded the results shown in Table 2. The EIS curves are very informative for comparing the stack operation under the two types of connection. Thus, (Figure 5) for MFC in series configuration (Figure 5a) higher values of resistances are recorded in comparison with the parallel configuration (Figure 5b).
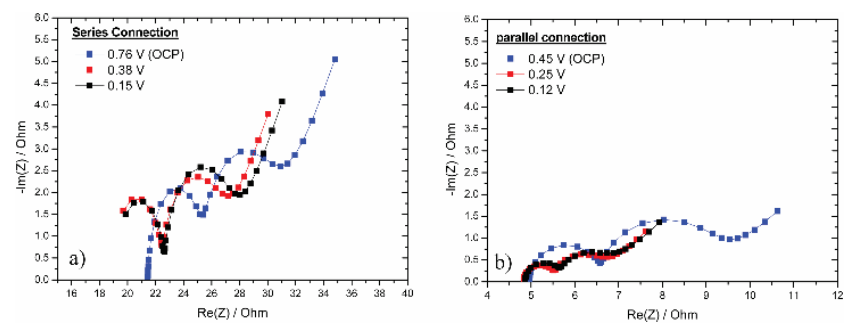

Figure 5. EIS fitted curves for the stack under (a) series connection and (b) parallel connection 
As shown from the calculated values in Table 2, the solution resistance $\left(R_{s}\right)$ of the stack is higher compared to the solution resistance which is observed under parallel configuration. In particular, the Rs obtained at OCVs $0.76 \mathrm{~V}, 0.38 \mathrm{~V}$ and at the end of the cycle ( $0.15 \mathrm{~V})$, for the in series connection it was equal to $21.45 \Omega, 18.80 \Omega$ and $19.6 \Omega$, respectively, whereas for the parallel connection it was equal to $4.96 \Omega, 4.83 \Omega$ and $4.86 \Omega$, for OCVs of 0.45 , 0.25 and $0,12 \mathrm{~V}$, respectively. Similarly, the charge transfer $\mathrm{C}_{\mathrm{CT}}$ and biofilm $\mathrm{C}_{\mathrm{BF}}$ capacitances are significantly higher in the case of in series connection than the respective values which are obtained in the parallel connection case. This result is in accordance with the assumption made from Figure $4 b$ that the no activation losses were observed and the power output reached the value of $3.88 \mathrm{~mW}$. The in series connection of the two-cell stack increases the overall resistance to the system as the charge transfer resistance $\left(R_{C T}\right)$ and the biofilm resistance $\left(\mathrm{R}_{\mathrm{BF}}\right)$ are calculated to be four times higher than the respective values under the parallel setup. These values of resistances and capacitances are evident to voltage drop phenomena on stack operation of MFCs giving a hint for the diminished power output of the series connection of MFCs (Oh and Logan, 2007; An et al., 2015).

Moreover, considering that the overall internal resistance (RINT) of the single cell is $12.71 \Omega$ (Tremouli et al., 2019), the internal resistances under both electrical configurations are in accordance with Fick's law. This means that besides OCV, the internal resistance values which are obtained under closed circuit are averaging the value of $27.0 \Omega$ and $6.65 \Omega$ under series and parallel connection, respectively. The slight differentiation from the theoretical values of the internal resistances of the cells in series and in parallel $(25.42$ and $6.35 \Omega$ respectively) is attributed to the losses in the electrode connections with the current collection probes.

\section{Conclusions}

The operation of a two - unit MFC stack was assessed under in series and parallel electrical configuration. The highest power output obtained was $3.88 \mathrm{~mW}$ under the parallel configuration, whereas the maximum power output for the series connection was $2.56 \mathrm{~mW}$. This phenomenon is attributed to batch cycle starvation and voltage drop of one of the cells in series. EIS measurements revealed that both under open and closed circuit conditions, the in series connection exhibited higher resistance values in comparison with the parallel connection. Consequently, stacking these units in parallel configuration is promising as the overall resistance of the stack is four times lower compared to series connection. Nevertheless, further experiments are ongoing in order to estimate the operation of larger stacks for the current cell structure and operation conditions along with optimization of electrodes.

\section{Acknowledgements}

This work was realized in the context of the Action "Financial support of Post-Doc Researchers" from the resources of OP Human Resources Development, Education and Lifelong
Learning 2014-2020, implemented by the State Scholarship Foundation (SSF) in Greece and co-funded from the European Social Fund ESF and the Greek Government.

\section{References}

Aelterman P., Rabaey K., Pam H., Boon N. and Verstraete W. (2006), Continuous Electricity Generation at High Voltages and Currents Using Stacked Microbial Fuel Cells. Environmental Science \& Technology, 40, 3388-3394.

An J., Kim B., Chang I.S. and Lee H.-S. (2015), Shift of voltage reversal in stacked microbial fuel cells. Journal of Power Sources, 278, 534-539.

Bennetto H.P. (1990), Electricity generatin by microorganisms. Biotechnology Education, 1, 163-168.

Chatzikonstantinou D., Tremouli A., Papadopoulou K., Kanellos G., Lampropoulos I. and Lyberatos G. (2018), Bioelectricity production from fermentable household waste in a dualchamber microbial fuel cell. Waste Management \& Research, 1-6, 0734242X18796935.

Freguia S., Rabaey K., Yuan Z. and Keller J. (2007), Non-catalyzed cathodic oxygen reduction at graphite granules in microbial fuel cells. Electrochimica Acta, 53, 598-603.

Gasparyan H., Argirusis C., Szepanski C., Sourkouni G., Stathopoulos V., Kharlamova T., Sadykov V.A. and Bebelis S. (2009), Electrochemical Characterization of a La0.8Sr0.2Ni0.4Fe0.6O3- $\delta$ Electrode Interfaced with La9.83Si5Al0.75Fe0.25026\{plus minus\} $\delta$ Apatite-type Electrolyte. ECS Transactions, 25, 2681-2688.

Gasparyan H., Neophytides S., Niakolas D., Stathopoulos V., Kharlamova T., Sadykov V., Van der Biest O., Jothinathan E., Louradour E., Joulin J.P. and Bebelis S. (2011), Synthesis and characterization of doped apatite-type lanthanum silicates for SOFC applications. Solid State lonics, 192, 158-162.

Greenman J., leropoulos I. and Melhuish C. (2011), Microbial fuel cells: Scalability and their use in robotics. in Eliaz, N., Applications of Electrochemistry and Nanotechnology in Biology and Medicine I.): Springer, pp. 239-290.

Hidalgo D., Sacco A., Hernandez S. and Tommasi T. (2015), Electrochemical and impedance characterization of Microbial Fuel Cells based on 2D and 3D anodic electrodes working with seawater microorganisms under continuous operation. Bioresource technology, 195, 139-146.

Lu N., Zhou S., Zhuang L., Zhang J.T. and Ni J.R. (2009), Electricity generation from starch processing wastewater using microbial fuel cell technology. Biochemical Engineering Journal, 43, 246-251.

Ntaikou I., Menis N., Alexandropoulou M., Antonopoulou G. and Lyberatos G. (2018), Valorization of kitchen biowaste for ethanol production via simultaneous saccharification and fermentation using co-cultures of the yeasts Saccharomyces cerevisiae and Pichia stipitis. Bioresource technology, 263, 75-83.

Oh S.-E. and Logan B.E. (2007), Voltage reversal during microbial fuel cell stack operation. Journal of Power Sources, 167, 1117.

Pandis P., Kharlamova T., Sadykov V. and Stathopoulos V.N. (2016a), Development of layered anode structures supported over Apatite-type Solid Electrolytes. MATEC Web of Conferences, 41, 04001.

Pandis P.K., Xenogiannopoulou E., Sakkas P.M., Sourkouni G., Argirusis C. and Stathopoulos V.N. (2016b), Compositional 
effect of $\mathrm{Cr}$ contamination susceptibility of La9.83Si6-xyAlxFeyO26 $\pm \delta$ apatite-type SOFC electrolytes in contact with CROFER 22 APU. RSC Advances, 6, 49429-49435.

Papaharalabos G., Greenman J., Stinchcombe A., Horsfield I., Melhuish C. and leropoulos I. (2014), Dynamic electrical reconfiguration for improved capacitor charging in microbial fuel cell stacks. Journal of Power Sources, 272, 34-38.

Ramasamy R.P. and Sekar N. (2013), Electrochemical Impedance Spectroscopy for Microbial Fuel Cell Characterization. Journal of Microbial \& Biochemical Technology.

Santoro C., Arbizzani C., Erable B. and leropoulos I. (2017), Microbial fuel cells: From fundamentals to applications. A review. Journal of Power Sources, 356, 225-244.

Tremouli A., Greenman J. and leropoulos I. (2018), Investigation of ceramic MFC stacks for urine energy extraction. Bioelectrochemistry, 123, 19-25.

Tremouli A., Intzes A., Intzes P., Bebelis S. and Lyberatos G. (2015), Effect of periodic complete anolyte replacement on the long term performance of a four air cathodes single chamber microbial fuel cell. Journal of Applied Electrochemistry, 45, 755-763.

Tremouli A., Martinos M., Bebelis S. and Lyberatos G. (2016), Performance assessment of a four-air cathode singlechamber microbial fuel cell under conditions of synthetic and municipal wastewater treatments. Journal of Applied Electrochemistry, 46, 515-525.

Tremouli A., Karydogiannis I., Pandis P.K., Papadopoulou K., Argirusis C., Stathopoulos V.N. and Lyberatos G. (2019), Bioelectricity production from fermentable household waste extract using a single chamber microbial fuel cell. Energy Procedia, Accepted proofs.

Zhao F., Slade R.C. and Varcoe J.R. (2009), Techniques for the study and development of microbial fuel cells: an electrochemical perspective. Chemical Society reviews, 38, 1926-1939.

Zhuang L., Zhou S., Wang Y., Liu C. and Geng S. (2009), Membrane-less cloth cathode assembly (CCA) for scalable microbial fuel cells. Biosensors \& Bioelectronics, 24, 36523656. 